Neil Donen MD, W. Amold Tweed MD, Sidney Dashfsky, Barry Guttormson EMT

\title{
The esophageal obturator airway: AN APPRAISAL
}

The use of the Esophageal Obturator Airway (EOA) was prospectively studied in 300 cases of prehospital cardiac arrests. Seventy-seven complications were documented in 72 patients. Inadvertent tracheal intubation occurred in 13 patients, five unrecognized. No differences were found when initial emergency room rhythm and resuscitation outcome were compared to a previous study using the oral ainway (OA). A subgroup of 124 EOA and $55 O A$ patients were compared. The EOA was effective in reducing the frequency of aspiration (17 vs 34 per cent). Arterial axygenation was similar, and rose in both groups following tracheal intubation. Esophageal trauma was found in 10 per cent of the EOA patients who undenvent autopsy. Although the EOA is useful in prehospital emergency care, the only advantage for this technique in comparison to the $O A$ is the prevention of aspiration of gastric contents. It also appears that other techniques of advanced cardiac life support, i.e. defibrillation, drug therapy. exc are necessary to improve survival statistics.

\section{Key words}

EQUIPMENT, AIRWAY: esophageal obturator, oral; VENTILATION: artificial.

From the Department of Araesthesia, University of Manitoba and the Winnipeg Ambulance Service, Winnipeg, Manitoba.

Address correspondence to: Neil Donen, MD, Critical Care Services, St. Boniface General Hospital, 409 Taché Avenue, Winnipeg, Manitoba, R2H 2 A6.

Supported in part by a grant from Manitoba Medical Services Corporation (Inc.).
The Esophageal Obturator Airway (EOA) was designed to provide an airway for the rescuer who cannot or is not allowed to intubate the trachea. ${ }^{1-3}$ In 1973 the American National Conference of Standards for cardiopulmonary resuscitation in emergency care endorsed its use as an effective and safe means of ventilating a comatose patient. ${ }^{4}$ In 1978 the Manitoba College of Physicians and Surgeons sanctioned the use of the EOA in the prehospital resuscitation of cardiopulmonary arrest victims by Emergency Medical Attendants (EMAs). Despite such endorsements, controversy still surrounds its use. Its opponents point out the lack of documentation regarding esophageal injury, inadvertent tracheal intubation, and gastric aspiration. $^{5,6}$

With the introduction of the EOA into prehospital use in the City of Winnipeg (1979) a prospective study was undertaken to answer these questions. This report covers its use in the first 300 patients.

\section{Materials and methods}

The EOA is inserted without the aid of a laryngoscope via the mouth, after the lower jaw has been pulled forward. The tube follows the natural curvature of the pharynx and enters the esophagus. With the mask seated on the face the cuff will lie below the level of the bifurcation of the trachea (Figure 1). The position of the obturator is confirmed by ventilating and auscultating the lungs. With the mask seated to the face, air can only pass down the trachea to inflate the lungs. For tracheal intubation, the face mask is detached and the tracheal tube inserted with the EOA in place. The obturator is removed once the tracheal tube cuff is inflated.

Before using the EOA in the field the EMAs completed 16 hours of training in anatomy and physiology of the respiratory system, physical examination of the lungs, and breath sound analysis. The technique of EOA insertion was first taught with mannikin practice, followed by further 


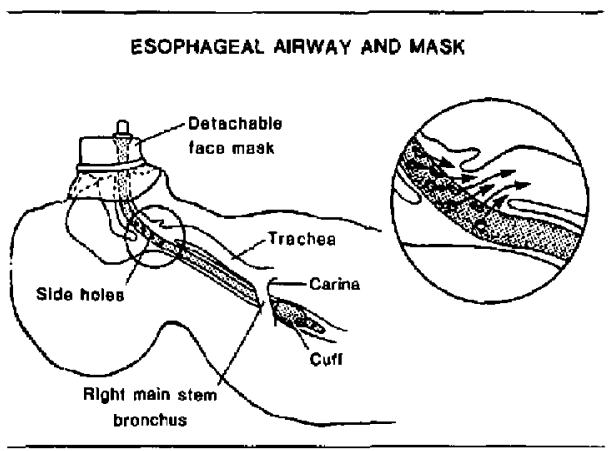

FIGURE 1 Position of EOA when mask sitting firmly on face. The tube is $37 \mathrm{cms}$. long and $13 \mathrm{~mm}$ in diameter. The clear plastic mask snaps onto the standard $15 \mathrm{~mm}$ connector. The distal end is blind with an inflatable cuff. The side holes near the upper end of the EOA permit egress of air from inside the tube into the pharynx.

practical sessions of EOA intubation of cadavers in the emergency room. An EMA was certified when he could consistently intubate the cadaver in less than 15 seconds. They were not trained to use other advanced cardiac life support measures such as defibrillation, endotracheal intubation or drugs. The EOA was used only in cases of cardiopulmonary arrest. Each use was recorded on a special data sheet indicating time spent at the scene of arrest, transportation time to hospital; initial rhythm and outcome of resuscitation in the hospital emergency room; number of attempts at intubation and problems or complications encountered by the EMAs and/or emergency room physicians. Transportation times, initial rhythms and resuscitation results were compared to those of a previous study in the City of Winnipeg during 1977-78 where only the oral air. way (OA) had been used. ${ }^{7}$

Because not all EMAs were certified in EOA usage the sudy protocol was expanded to a comparative study of the EOA, OA, and tracheal tube in a subgroup of patients transported to the two university hospitals in Winnipeg. Evaluation included effectiveness of oxygenation, acid-base status, prevention of regurgitation, and frequency of esophageal trauma in the EOA group. The study protocol called for arterial blood gas samples both prior to and five to eight minutes after tracheal intubation, with the initial blood gas sample to be drawn before bicarbonate therapy was instituted. All patients, irrespective of airway, were ventilated with 100 per cent oxygen. Only patients with both pre- and post-tracheal intubation $\mathrm{PO}_{2}$ of $45 \mathrm{mmHg}$ or greater were included in the analysis of data. This ensured that all samples were of arterial origin. To evaluate the metabolic acjd-base status of the patients, all pH's were corrected to a standardized $\mathrm{PCO}_{2}$ of $40 \mathrm{mmHg}{ }^{8}$ The EMAs and physicians were also asked to document the presence or absence of vomitus in the upper airway at the time of EOA, OA or tracheal tube insertion. Approval for this aspect of the study was obtained from the Faculty Committee on the use of Human Subjects in Research at the University of Manitoba.

In all EOA patients in the subgroup who were autopsied, the extent and site of damage occurring in the esophagus was noted. Chest $x$-rays and intensive care unit progress notes of survivors were also reviewed for evidence of subcutaneous or mediastinal cmphysema, or other clues of esophageal damage.

Data were statistically analyzed using either a two-sample t-test (paired observations or independent samples), Mann-Whitney U-Ranking or Chi-square analysis tests for significance.

\section{Results}

\section{A Overall group}

The majority of cardiorespiratory arrests were secondary to cardiac disease. Other causes included trauma, drowning and suicide attempts. The majority of the patients were between the ages of 50-70 years. Seventy-six per cent of the victims were males. With respect to transportation times, the average time from "911" call to hospital arrival was 20 minutes.

$1 /$ INITIAL RHYTHM AND RESUSCITATION (Table I) Complete information on initial emergency room rhythm and resuscitation outcome was available in 228 of the 300 cases. Asystole was the predominant initial thythm seen ( 66 per cent), while ventricular fibrillation or tachycardia was found in another 25 per cent of cases. These figures do not differ significantly from the 1977-78 control group. When ventricular fibrillation/tachycardia was the initial thythm, 14 patients (25 per cent) were admitted to the intensive care unit compared to 31 per cent in the control group. The difference is not statistically significant. 
TABLE I Initial shythm and resuscitation in the hospital emergency room

\begin{tabular}{lcclll}
\hline & \multicolumn{2}{l}{ EOA $(1979-81)^{*}$} & & \multicolumn{2}{l}{$O A(1977-78) \dagger$} \\
\cline { 2 - 3 } \cline { 5 - 6 } & Total & Resuscitated & Total & Resuscitared \\
\hline Asystole & $151(66 \%)$ & $9(6 \%)$ & & $495(58 \%)$ & $65(13 \%)$ \\
VF/VT & $56(25 \%)$ & $14(25 \%)$ & & $226(27 \%)$ & $69(31 \%)$ \\
Other & $21(9 \%)$ & $12(57 \%)$ & & $125(15 \%)$ & $50(40 \%)$ \\
Recorded & 228 & $35(15 \%)$ & & 849 & $184(22 \%)$ \\
\hline
\end{tabular}

EOA - Esophageal Obturator Airway

$\mathrm{OA}$ - oral airway.

VF/VT - ventricular fibrillation/tachycardia.

*The initial rhythm or survival was not recorded in 72 patients. $\dagger$ Tweed et al. ${ }^{7}$

Resuscitated - cardiac action restored and patient transferred to the intensive care unit.

TABLE 11 Problems encountcred with esophageal obturator airway use in 72 patients

\begin{tabular}{lrll}
\hline $\begin{array}{l}\text { Emergency Medical } \\
\text { Attendant }\end{array}$ & & & Emergency Physician \\
\hline Technical/equipment & 8 & Unfamiliarity & 7 \\
Unable to pass EOA & 11 & EOA removed prior & \\
& & to tracheal intubation & 13 \\
Tracheal intubation & 13 & Difficult intubation & 13 \\
& & Not recorded & 12 \\
& $\mathbf{3 2}$ & & 45 \\
\hline
\end{tabular}

EOA = Esophageal Obturator Airway.

$2 /$ PROBLEMS ASSOCIATED WITH EOA USE (Table II) A total of 77 complications were encountered in 72 patients. Emergency room physicians recorded 45 complications. The commonest reasons listed for removing the EOA prior to tracheal intubation was either an inability to visualize the vocal cords adequately or difficulty intubating with the EOA in place. Nonc of the 13 patients aspirated following removal of the EOA prior to endotracheal intubation. Anterior position of the larynx was listed as the reason in six of the 13 difficult intubations. Individuals with short thick necks accounted for another four patients. Seven physicians had never seen an EOA before. Emergency medical attendants recorded 32 complications. Leaking balloons or holes in the mask were the commonest causes of equipment failure. In 11 patients (4 per cent) the EOA could not be passed or the "fit" was considered to be tight. Multiple attempts of EOA insertion were
TABLE III Esophageal damage following esophageal obturator airway (EOA) insertion occurring in 7 patients*

\begin{tabular}{ll}
\hline Damage & Site $\dagger$ \\
\hline 1 cm mucosal laceration & Upper \\
Contusion & Upper \\
$14 \mathrm{~cm}$ mucosal laceration & Upper/middle \\
Rerro-esophageal haematoma & Middle \\
$1.5 \mathrm{~cm}$ mucosal laceration & Middle \\
$6 \mathrm{~cm}$ mucosal laceration & Middle \\
$3 \mathrm{~cm}$ mucosal laceration & Middle \\
\hline
\end{tabular}

*Findings from 70 autopsies.

tSite: Upper or middle third of esophagus.

‡EOA inserted a number of times after death.

associated with an increase in problems documented by the EMAs. The trachea was accidentally intubated in 13 patients ( 4 per cent). In eight cases this was recognized by the EMA and the EOA was either correctly re-inserted or an oral airway substituted. Four of these unrecognized tracheal intubations occurred in the first 50 cardiac artcsts attended. The fifth patient was described as being obese and in pulmonary edema. The EOA had been re-inserted as the attendants were not sure of its position with the first attempt. All of these five patients died.

\section{B Subgroup}

One hundred and twenty-four EOA and 55 OA patients comprised the subgroup intensively studied.

1 / ESOPHageal TRauma (Table III)

Autopsies were performed on 70 of the $106 \mathrm{EOA}$ patients who died. No cases of esophageal rupture were found but esophageal damage was noted in seven patients (10 per cent). Five had mucosal lacerations, with damage involving either the upper or middle portions of the esophagus. One patient, in whom a $14 \mathrm{~cm}$ mucosal laceration was noted had an EOA inserted several times after death. Two attempts at EOA insertion were made in a patient with a laceration of the upper esophagus. The remaining five patients required only one attempt at EOA insertion. No clinical evidence of esophageal rupture was found in 18 patients surviving initial resuscitation. This included three persons who underwent esophagoscopy.

\section{2/ ASPIRATION}

Adequate information concerning the presence or absence of vomitus in the upper airway at the time 
TABLE IV Vomitus noted in upper airway at hospital

\begin{tabular}{lll}
\hline & $E O A$ & $O A$ \\
\hline No & 76 & 23 \\
Yes & $16(17 \%)$ & $12(34 \%)$ \\
Not recorded* & $32(26 \%)$ & $20(36 \%)$ \\
Total & $\frac{124}{55}$ & $\frac{5}{124}$
\end{tabular}

EOA $=$ Esophageal Obturator Airway

$\mathrm{OA}=$ oral airway.

$p<0.05$ by Chi-square test.

*Information was not documented clearly on the data sheet:

i.e. "Vomitus present or absent".

of tracheal intubation was recorded in 127 of the 179 patients studied (Table IV). Vomitus was noted in 17 per cent of those who had an EOA inserted compared to 34 per cent of those with an OA $(p<$ 0.05 ). Nine of the 16 patients in whom vomitus was observed at tracheal intubation had regurgitated prior to EOA insertion.

\section{3 / OXYGENATION}

Sixteen patients (13 per cent) with EOA and 10 patients ( 18 per cent) with the OA met our criteria for assessment of arterial oxygenation, i.e. $\mathrm{PO}_{2}$ 's of $45 \mathrm{mmHg}$ or greater both pre- and post-tracheal intubation. Figure 2 shows $\mathrm{PO}_{2}$ results before and after tracheal intubation. Median values for the pre-tracheal $\mathrm{PaO}_{2} \mathrm{~s}$ were similar for the $\mathrm{OA}$ (118 $\mathrm{mmHg}$ ) and the EOA (123 $\mathrm{mmHg}$ ), as were the $\mathrm{PO}_{2}$ values post-intubation; $\mathrm{OA} 305 \mathrm{mmHg}$ and EOA $297 \mathrm{mmHg}$. When all prc-tracheal intubation gases were grouped together and compared to all those post-tracheal intubation, the rise in oxygenation following tracheal intubation was significant $(p<0.01)$. The pooled median $\mathrm{PO}_{2}$ values rose from an initial $122 \mathrm{mmHg}$ to $305 \mathrm{mmHg}$ following tracheal intubation.

TABLE V Acid-base status: before bicarbonate therapy

\begin{tabular}{|c|c|c|c|}
\hline & $E O A$ & $O A$ & \\
\hline No. of patients & 34 & 29 & \\
\hline pH (units) & $7.23 \pm 0.03$ & $7.19 \pm 0.03$ & \\
\hline $\mathrm{PaCO}_{2}\left(\mathrm{mmH}_{\mathrm{g}}\right)$ & $34 \pm 2$ & $42 \pm 3$ & NS \\
\hline $\begin{array}{l}\mathrm{pH} \text { corrected (units) } \\
\left(\mathrm{PaCO}_{3} \text { of } \mathbf{4 0} \mathrm{mmHg}\right)\end{array}$ & $7.19 \pm 0.02$ & $7.21 \pm 0.02$ & NS \\
\hline
\end{tabular}

Results: Mean \pm S.E.M.

EOA $=$ Esophageal Obturator Airway.

$O A=$ oral airway.

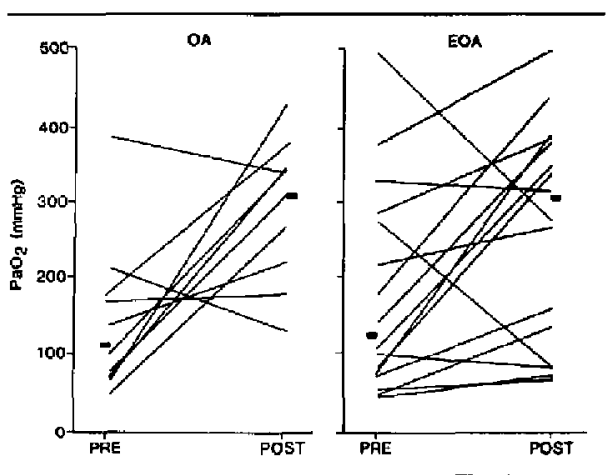

FIGURE 2 Oxygenation before (pre) and after (post) tracheal intubation. EOA = Esophageal Obturator Airway Group; $\mathrm{OA}=$ Oropharyngeal Airway Group; $=$ Median Values.

\section{4 / ACID-BASE STATUS (Table V)}

There were no statistically significant differences in $\mathrm{PaCO}_{2}$ and $\mathrm{pH}$, corrected and uncorrected, when comparing the two groups. When the $\mathrm{pH}$ values were corrected to a standardized $\mathrm{PCO}_{2}$ of $40 \mathrm{mmHg}$, a moderate metabolic acidosis was noted.

\section{Discussion}

Tweed (our control group) ${ }^{7}$ and Eisenberg ${ }^{9}$ documented a significant increase in survival when the time between the emergency call and advanced life support (hospital and paramedics respectively) was ten minutes or less. The patients reported here were without definitive treatment for approximately 20 minutes. We found no improvement in initial rhythm status or frequency of successful resuscitation in patients ventilated with the EOA. We conclude that the EOA alone does not improve survival and advanced cardiac life support, including defibrillation and drug therapy within ten minutes of arrest, will be required to change survival statistics.

A continued complaint by the EMAs was the problem of maintaining an adequate seal by the EOA face mask. This proved to be particularly troublesome with one man CPR. This has been noted by others. ${ }^{10}$ Although it is simple to document the problem, it is extremely difficult to assess such factors as adequacy of oxygenation en route to hospital. A simple solution may be to design a strap which could hold the mask on the face contin- 
uously. The finding that in 4 per cent of cases the EOA could not be passed or was a tight fit is in keeping with those of Gordon." There was a recurring pattern of difficulties with airway cannulation in bull-necked individuals by both the EMAs and emergency room physicians. Although not a major problem, it is still useful to recognize the type of patient in whom difficulty may be anticipated. The other patients in whom removal of the EOA prior to tracheal intubation may be necessary are people of small stature. Seven emergency room physicians had never seen an EOA before and had technical problems with inserting a tracheal tube and removing the EOA. Clearly, if the EOA is to be used it is essential that all personnel involved with its use must be trained.

The frequency of inadvertent tracheal intubation varies between five and ten per cent. ${ }^{3}$ Our own incidence was 4 per cent, and was unrecognized in 2 per cent. However, four of the five cases occurred in the first six months of clinical usage. The criteria for assessment and recognition of tracheal intubation were then reviewed and discussed with the EMAs. All eight recognized cases of tracheal intubation occurred after the review session, and only one recognized tracheal intubation occurred in the last 250 patients. Clearly, adequate teaching of physical signs and discussion about recognition of tracheal intubation, coupled with a careful assessment following EOA insertion, can dramatically reduce the incidence of this fatal complication. The true incidence of esophageal perforation after EOA insertion has never been accurately determined. Estimates between zero ${ }^{12}$ and two per cent ${ }^{13}$ have only been determined from the population of survivors. Only 20 cases of esophageal perforation following EOA insertion are documented in the literature. ${ }^{14,15}$ In EOA earlier models, lacerations of the mucous membrane of the upper esophagus or pharynx occurred due to the bullet shape of the occluding tip of the esophageal tube. The tip was subsequently modified to a hemispheric shape. ${ }^{11}$ Despite this change two of our patients demonstrated trauma to the upper esophagus. In our series of 70 autopsied patients, seven (ten per cent) had damage to the esophagus, though no clear cases of rupture were found. The common sites of reported esophageal rupture have been the middle and distal thirds of the esophagus. Five of our patients in whom the EOA was inserted once showed damage in these areas. Thus, although no full thickness tears were noted, at least seven per cent of our autopsied patients showed the potential to rupture. If the true incidence of esophageal rupture is to be assessed, a much larger group of patients needs to be studied.

Several authors claim the EOA reduces the incidence of regurgitation and subsequent aspiration. ${ }^{2,10,11}$ However, this has never been systematically evaluated. We have shown that the obturator significantly reduces regurgitation as compared to the oral airway. In addition nine of the $16 \mathrm{EOA}$ patients with regurgitation at hospital had alrcady vomited prior to the arrival of the ambulance attendants. Therefore, the EOA may be even more efficient at preventing regurgitation than our results show.

Studies by Schofferman ${ }^{16}$ and Meislin ${ }^{17}$ concluded that oxygenation using an EOA was as effective as tracheal intubation. In contrast, although our study shows that both the EOA and OA provide adequate oxygenation, our results indicate that tracheal intubation provides better oxygenation than either. Thus we believe that tracheal intubation is the preferted method for delivering oxygen.

The acid-base results represent the pre-treatment status prior to bicarbonate administration. The finding that only a moderate metabolic acidosis was present was expected, considering the patients had received only basic cardiac life support and oxygen therapy over the preceding 20 minutes. The implications of these findings, coupled with the mild hyperventilation occurring with the chest compression ventilation ratio of $5: 1$, need to be revicwed in more detail.

It is important to stress that complications do occur and one should know how to both prevent and recognize them. Training of EMAs should include didactic and interactive teaching on EOA usage, anatomy and physiology of the respiratory system, as well as physical examination and auscultation. Practical sesstons with both mannikins and cadavers should be mandatory prior to permitting unsupervised use of the EOA by the EMAs. The two-hour training recommended by some ${ }^{3}$ is in our experience inadequate to ensure competency in the use of the Esophageal Obturator Airway.

We have not attempted to compare the EOA with tracheal intubation except with respect to oxygenation. There are no detailed studies in the pre- 
hospital setting of the frequency of complications and difficulties associated with tracheal intubation. Of interest, is a report by Taryle ${ }^{18}$ who documented 24 complications in 43 patients intubated with a tracheal tube in an emergency department. The departmental origin or level of training of the intubator did not affect the rate of complications.

In summary, the EOA appears to offer the single advantage of reducing frequency of aspiration when compared to the oral airway. This factor alone recommends its use in the pre-hospital setting when tracheal intubation is not possible.

\section{Acknowledgements}

Secretarial assistance by Debbie Kilbome and the co-operation of the Emergency Medical Attendants of the Winnipeg Ambulance Service and the emergency room physicians and nurses of the various Winnipeg Hospitals is gratefully acknowledged.

\section{References}

1 Don Michael TA, Lambert EH, Mehran A. "Mouthto-lung airway" for cardiac resuscitation, Lancet 1968; 2: 1329 .

2 Don Michat TA. The Esophageal Obturator Airway. A critique. JAMA 1981; 246: 1098-1 101

3 Don Michael TA, Gordon AS. The Esophageal Obturator Airway: a new device in emergency cardiopulmonary resuscitation. $\mathrm{Br}$ Med J 1980; 281: 1531-4.

4 Standards for carciopulmonary resuscitation (CPR) and emergency cardiac care (ECC). JAMA 1974; 227 (Suppl): 833-68.

5 Benumof J, Ward CF. Communications to the Editor (Reply). Chest 1979; 5: 613.

6 Safar $P$. Discussion. Improved Esophageal Obturator Airway (EOA) and new esophageal gastric tube airway (EGTA), In: Safar P, Elam J, eds. Advances in Cardiopulmonary Resuscitation. New York: Springer-Verlag, 1977: 63.

7 Tweed WA, Bristow G, Donen N. Resuscitation from cardiac arrest: Assessment of a system providing only basic life support outside of hospital. Can Med Assoc J 1980; 122: 297-300.

8 Sladen A. Acid-base balance. In: McIntyre KM, Lewis AJ, eds. Textbook of Advanced Cardiac Life Support. American Heart Association, 1981: Chapter $X$.
9 Eisenberg MS, Bergner L, Hallstrom A. Out-ofhospi:al cardiac arrest: improved survival with paramedic services. Lancet 1980; 1: 812.

10 Meislin HW. The Esophageal Obturator Airway; it works, but ... Ann Emerg Med 1980; 9; 171.

11 Gordon AS. Improved Esophageal Obturator Airway (EOA) and new esophageal gastric tube airway (EGTA). In: Safar P, Elam J, eds. Advances in Cardiopulmonary Resuscitation. New York: Springer-Verlag, 1977: 58-64.

12 Smock SN. Esophageal Obturator Airway: preferred CPR technique. JACEP 1975; 4: 232.

13 Strate RG, Fischer RP. Midesophageal perforations by Esophageal Obturator Airways. J Trauma 1976; 16: 503-9.

14 Harrison EE, Nord HJ, Beeman RW. Esophageal perforation following use of the Esophageal Obturator Airway. Ann Emerg Med 1980; 9; 21-5.

15 Kassels SJ, Robinson WA, O'Bara KJ. Esophageal perforation associated with the Esophageal Obturator Airway, Crit Care Med 1980; 8: 386-9.

16 Schofferman J, Oill $P$, Lewis AJ. The Esophageal Obturator Airway. A clinical evaluation. Chest 1976:69: 67-9.

17 Meislin $H W$. The Esophageal Obturator Airway: a study of respiratory effectiveness. Ann Emerg Med 1980; 9: 54-9.

18 Taryle DA, Chandler JE, Good JT, Potts DE, Sahn $S A$. Emergency room intubating - complications and survival. Chest 1979; 75: 541-3. 
Résumé

Nous avons examiné l'emploi du tube obturateur asophagien (EOA) dans 300 cas de patients souffrant d'arrêt cardiaque en pré-hospitalisation. Nous avons trouve 77 complications chez 72 patients. L'intubation trachéale maladroile fut observée chez 23 patients dont cinq ne furent pas reconnues. On n'observa pas de differences lorsque les rhythmes après réanimation furent pratiqués dans la salle d'urgence en comparaison d une étude précédente employant le tube par voie orale $(O A)$.

Un sous-groupe de 124 patients a été examiné avec l'emploi du tube obturateur asophagien (EOA) et comparé a un autre sous-groupe de 55 patients examiné avec le tube par voie orale (OA). Le EOA fut efficace pour la réduction de la fréquence en aspiration (17 versus 34 pour cent). L'oxygénation artérielle fut similaire et augmenta chez les deux groupes après l'intubation trachéale. Le traumatisme de l'asophage fut observé chez 10 pour cent des parients sur qui une autopsie fut pratiquée. Quoique l'usage du tube obturateur asophagien soit utile dans les cas de préhospitalisation dans les cas d'urgence, le seul avantage qu'il présente avec celte technique en comparaison avec le tube par voie orale est la prévention de l'aspiration des contenus gastriques. Il est apparent que d'autres techniques pour troubles cardiaques aigüs, c'est-adire la défibrillation, l'usage des drogues etc., sont nécessaires afin d'améliorer les statistiques de survie. 